\title{
PERFORMANCE OF A BRAZILIAN \\ POPULATION IN THE EC 301 CALCULATION \\ AND NUMBER PROCESSING BATTERY
}

\author{
A pilot study
}

\author{
Gabriela De Luccia', Karin Zazo Ortiz²
}

\begin{abstract}
Background: From a neuropsychological point of view calculation is a very complex function. A simple arithmetic operation demands many neurocognitive mechanisms that involve verbal, spatial and graphical processing, memory and attention. Objective: To verify the calculation and number processing of healthy subjects and the effect of gender, age and schooling on their performance. Method: Forty-four normal subjects without complaints or neurological changes were evaluated. Results: The educational level was significantly linked to performance in the majority of tests of the EC 301 battery, whereas no differences were noted regarding age and gender. Conclusion: Evaluation of the data of the healthy population shown in this study indicated that educational level can affect calculation and number processing, It is possible to note that battery EC 301 demonstrated sensitivity for appraisal of these abilities and therefore can be employed for clinical assessment in calculation and number disorders.
\end{abstract}

KEY WORDS: mathematics, population characteristics, calculation ability, numerical knowledge, acalculia.

\section{Desempenho da população brasileira no processamento numérico e de cálculo através da bateria EC 301: estudo piloto}

Resumo - Introdução: O cálculo do ponto de vista neuropsicológico é uma função muito complexa. Em uma simples operação aritmética estão envolvidos diversos processos neurocognitivos que envolvem os processamentos verbais, espaciais, gráficos, atenção e memória. Objetivo: Este estudo teve por objetivo verificar o desempenho de indivíduos saudáveis, no processamento numérico e de cálculo, através da bateria EC 301 e verificar as interferências do sexo, da idade e da escolaridade no desempenho destes indivíduos. Método: Foram avaliados 44 sujeitos normais sem queixas e/ou alterações neurológicas. Resultados: O nivel educacional mostrou-se fortemente relacionado ao desempenho obtido na maioria das provas da bateria $\mathrm{EC} 301$, enquanto em relação ao sexo e idade não foram encontradas diferenças. Conclusão: Os dados encontrados na população avaliada neste estudo mostraram que o nível educacional pode influenciar o desempenho do processamento numérico e de cálculo, sendo possivel observar que a bateria EC 301 mostrou-se sensivel para avaliar estas habilidades, podendo assim ser utilizada na avaliação clínica dos distúrbios numéricos e de cálculo.

PALAVRAS-CHAVE: matemática, características populacionais, habilidade de calcular, conhecimento numérico, acalculia

The ability to calculate is an extremely complex cognitive procedure. It consists of multifactorial processes, including verbal and spatial abilities, memory and executive functions'. Realization of mathematical calculations can be impaired in cases of cerebral dysfunction and/or injuries $^{2-6}$ as well as in dementias ${ }^{7,8}$. The loss of the ability to perform calculation tasks resulting from a cerebral pathology is known as acalculia or acquired dyscalculia.

\footnotetext{
'Doutora em Ciências; ${ }^{2}$ Professora Adjunta do Departamento de Fonoaudiologia, Universidade Federal de São Paulo - UNIFESP, São Paulo SP, Brazil. Financial Suporte: Fundo de Amparo à Pesquisa do Estado de São Paulo (FAPESP, no 0346/04).
}

Received 4 November 2008, received in final form 11 March 2009. Accepted 5 May 2009.

Dra. Gabriela De Luccia - Rua Esmeralda 674 / 102 - 78050-050 Cuiabá MT - Brasil. E-mail: gabideluccia@hotmail.com 
Acalculia has been defined as an acquired disturbance in computational ability. The developmental defect in the acquisition of numerical abilities, on the other hand, is usually referred to as developmental dyscalculia (DD) or dyscalculia, ${ }^{9,10}$. Acalculia is frequently mentioned in neurological and neuropsychological clinical reports, but specific research directed to the analysis of acalculia is rather limited. The lesions in the areas of language in the left cerebral hemisphere produce alterations in comprehension and in the production of numbers, and therefore in carrying out the arithmetical operations ${ }^{11}$. On the contrary, the lesions in the right cerebral hemisphere cause alterations in spatial organization of quantities and in comprehension and achievement of abstract problems ${ }^{1,4}$.

The cortical areas in patients with brain injury that have been studied by neural-imaging and the results accepted in the literature have shown that areas of the parietal lobe with involvement of the temporal areas and intraparietal sulcus, can be more susceptible to cause isolated mathematical changes ${ }^{12,13}$. However, broad cortical injuries that also involve regions proximal to the left temporal cortex, left and right parietal and frontal lobe, are susceptible to conduct concomitant language disorders and numerical and calculating processing ${ }^{13-16}$.

Mathematical calculation exists in many everyday activities. Calculation ability under normal circumstances requires not only the comprehension of numerical concepts, but also that of conceptual abilities and other cognitive skills. In the neuropsychological domain, however, just a few research has been carried out to explore the relationship between mathematical test performance and performance of other cognitive tests'. Considering these perspectives, in countries such as Brazil, with a broad socio-cultural diversity, cognitive tasks should always be investigated in the healthy population since factors such as gender, schooling and age can affect cognitive performance on other cognitive tests ${ }^{17,18}$. Few neuropsychological studies have taken into account the question of calculation abilities in the general population. Intuitive observation points to a significant dispersion of arithmetical abilities in healthy subjects. Usually, however, it is assumed that any normal person should be able to use onedigit multiplication tables, to use the four basic arithmetical operations, to solve simple arithmetical problems, to memorize seven digits after a single presentation, and to use diverse numerical information in everyday life ${ }^{19}$. Nonetheless, normative studies are scarce.

The EC 301 battery was developed in 1994 by Deloche et al..$^{77}$ for evaluation of adults with impairment of calculation and number processing after brain damage. To obtain populational data, the battery was initially applied to 180 subjects, grouped by schooling, gender and age. The analysis of error rates indicated the effect of some demo- graphic factors, particularly education, since subjects with less schooling exhibited poorer performance in counting tests, transcodification, written verbal numbers, comparisons of magnitude, and subtests of arithmetic operations. Incidentally, in total mental calculations ${ }^{20,21}$, males performed better in Arabic numbers and counting. Age did not influence the groups studied ${ }^{17}$. Considering that variables i.e., gender, age and education could have an impact on the calculations, the objective of this study was to verify their effect on the performance of healthy Brazilian individuals, in calculation and number processing. This is a pilot study presenting a profile of Brazilian adults on the EC 301 battery.

\section{METHOD}

All data was collected after approval of the study by the Ethics and Research Committee of the UNIFESP (file no. 0346/04) Written informed consent was obtained from all enrolled subjects, subsequent to receiving full information about the study.

\section{Subjects}

Forty-four volunteers were selected (74\% female). Average education was $8.5 \pm 4.1$ years and age, was $40.6 \pm 16.0$ years $R e-$ garding education, the participants were divided by years and schooling. Four groups were formed: 1-5 years with 14 participants, 6-8 years, 12 participants, 9-12. years 11 participants and more than 12 years of schooling with 7 participants. Based on age, the participants were divided into 2 groups, the elderly group consisting of those over 60 and the young group between 18 and 59 years including 38 young subjects.

Inclusion criteria were subjects without language, calculation or memory problems, over 18 years of age and a minimum of one year's schooling. Excluded were participants with a diagnosis or history of auditory, psychiatric and/or neurological problems, such as epilepsy, stroke, traumatic brain injury with more than 15 minutes loss of conscience, or psychotropic drug users. The participants were submitted to the 31 subtests composing the EC 301 battery for evaluation of calculation and number processing, developed by Deloche ${ }^{17}$.

\section{Procedure}

The tests were applied in a quiet room, over one or two sessions, on different days, and lasted about an hour each, respecting the individual limits of each participant. There was no time limit for executing the tasks. Paper and pencil were utilized for the tests and only one person applied the tests to all the individuals.

\section{Material}

The EC301 battery was applied. The EC301 calculation battery consists of 13 different tasks, some of which include subtasks:

1. Counting ( 3 subtasks, $\mathrm{Cl}, \mathrm{C2}, \mathrm{C} 3$ ). The subject must use different codes (phonological, Arabic, and orthographic) to produce 


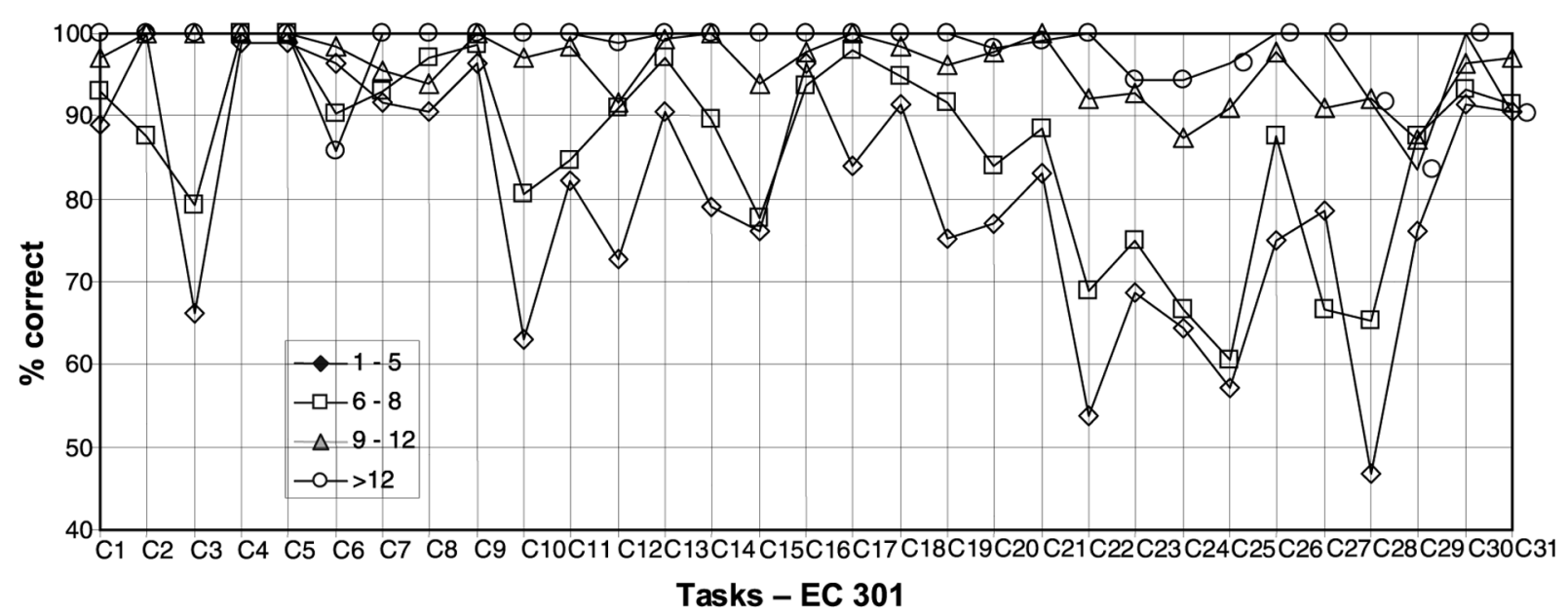

Figure. Average percentage of correct responses in each subtest of test battery EC301 according to years of schooling (n de 1-5=14; 6-8=12, 9-12=11 e >12=7).

a somewhat automatic sequence of numbers, backwards and forwards, according to different ratios (by one, by three, by ten).

2. Dot counting ( 5 subtasks, C4, C5, C6, C7, C8). This task evaluates the capacity to compute the cardinality of a set of discrete elements (dots) with different spatial arrangements. The subject is required to point to the dots while counting aloud.

3. Transcoding (7 subtasks $\mathrm{C} 9, \mathrm{C10}, \mathrm{C11}, \mathrm{C12}, \mathrm{C13}, \mathrm{C14}, \mathrm{C15}$ ). These subtasks correspond to the six possible transcodifications between the phonological, the Arabic, and the orthographic codes, and number repetition. Items were selected so as to make their lexico-syntactical structure directly comparable from one subtask to another.

4. Arithmetical signs ( 2 subtasks, $\mathrm{C16}, \mathrm{C17}$ ). The subject is required to name the arithmetical signs and to write them as dictated.

5. Number comparison (2 subtasks, C18, C19). The subject is required to point to the greater of two numbers, presented both in the Arabic (8 items) or in the orthographic form (8 items).

6. Mental computation ( 2 subtasks, C20, C21). This task evaluates mental calculation requiring the subject to access knowledge of number facts, and to perform simple operations.

7. Estimation of the result of an operation (1 subtask, C22). Subjects have to point to the best approximation (among four alternatives) of the correct result of a complex operation.

8. Number positioning on an analogical scale (2 subtasks, C23, C24). A vertical line graded from 0 to 100 is shown to the subject who must place a spoken or a written Arabic number on the line, choosing among one of three possible positions.

9. Writing down an operation (1 subtask, C25). The subject is requested to copy a pair of two- or three digit numbers, placing them in the conventional way for the written operation, corresponding to a given arithmetical sign.

10. Written calculation ( 3 subtasks, C26, C27, C28). This task tests the subject's ability to perform sums, subtractions and mul-
Table 1. Descriptive analysis of percentage scores of battery EC 301 subtests.

\begin{tabular}{|c|c|c|c|c|c|}
\hline Subtests & Average & SD & Mean & Minimum & Maximum \\
\hline $\mathrm{Cl}$ & 93.5 & 12.2 & 100.0 & 62.5 & 100,0 \\
\hline $\mathrm{C} 2$ & 96.6 & 12.7 & 100.0 & 50.0 & 100,0 \\
\hline $\mathrm{C} 3$ & 83.5 & 30.0 & 100.0 & 0.0 & 100,0 \\
\hline $\mathrm{C} 4$ & 99.6 & 2.5 & 100.0 & 83.3 & 100.0 \\
\hline $\mathrm{C} 5$ & 99.6 & 2.5 & 100.0 & 83.3 & 100.0 \\
\hline C6 & 93.6 & 13.1 & 100.0 & 50.0 & 100.0 \\
\hline $\mathrm{C7}$ & 94.3 & 12.4 & 100.0 & 50.0 & 100.0 \\
\hline $\mathrm{C} 8$ & 94.7 & 12.3 & 100.0 & 50.0 & 100.0 \\
\hline $\mathrm{C} 9$ & 98.5 & 4.5 & 100.0 & 83.3 & 100.0 \\
\hline $\mathrm{C} 10$ & 82.2 & 26.3 & 100.0 & 0.0 & 100.0 \\
\hline $\mathrm{C} 11$ & 89.8 & 19.1 & 100.0 & 0.0 & 100.0 \\
\hline $\mathrm{C} 12$ & 86.6 & 22.6 & 95.8 & 0.0 & 100.0 \\
\hline $\mathrm{C} 13$ & 96.0 & 15.6 & 100.0 & 0.0 & 100.0 \\
\hline $\mathrm{C} 14$ & 90.5 & 18.1 & 100.0 & 0.0 & 100.0 \\
\hline $\mathrm{C} 15$ & 84.8 & 21.5 & 100.0 & 0.0 & 100.0 \\
\hline $\mathrm{C} 16$ & 96.6 & 8.7 & 100.0 & 75.0 & 100.0 \\
\hline $\mathrm{C} 17$ & 94.3 & 17.8 & 100.0 & 0.0 & 100.0 \\
\hline $\mathrm{C} 18$ & 95.3 & 7.6 & 100.0 & 75.0 & 100.0 \\
\hline $\mathrm{C} 19$ & 88.8 & 18.9 & 100.0 & 0.0 & 100.0 \\
\hline $\mathrm{C} 2 \mathrm{O}$ & 87.4 & 19.6 & 100.0 & 25.0 & 100.0 \\
\hline $\mathrm{C} 21$ & 91.3 & 18.6 & 100.0 & 25.0 & 100.0 \\
\hline $\mathrm{C} 22$ & 74.7 & 29.5 & 87.5 & 0.0 & 100.0 \\
\hline $\mathrm{C} 23$ & 80.5 & 28.8 & 100.0 & 0.0 & 100.0 \\
\hline $\mathrm{C} 24$ & 75.5 & 32.5 & 100.0 & 0.0 & 100.0 \\
\hline $\mathrm{C} 25$ & 72.7 & 39.9 & 100.0 & 0.0 & 100.0 \\
\hline $\mathrm{C} 26$ & 88.1 & 28.3 & 100.0 & 0.0 & 100.0 \\
\hline $\mathrm{C} 27$ & 81.8 & 30.7 & 100.0 & 0.0 & 100.0 \\
\hline $\mathrm{C} 28$ & 70.5 & 34.9 & 71.4 & 0.0 & 100.0 \\
\hline $\mathrm{C} 29$ & 83.1 & 20.5 & 83.3 & 16.7 & 100.0 \\
\hline C30 & 94.5 & 12.5 & 100.0 & 40.0 & 100.0 \\
\hline C31 & 92.4 & 10.5 & 100.0 & 66.7 & 100.0 \\
\hline
\end{tabular}

SD: standard deviation. 
tiplications, which involve access to numerical facts and calculation procedures such as carrying and borrowing.

11. Perceptive estimation of quantity (1 subtask, C29). Subjects have to provide an estimate of weight, length or number of objects shown in a picture.

12. Contextual magnitude judgments (1 subtask, C30). Given a specific and contextual situation, the subject is asked to give an interpretation of numerical size (i.e.: in a class of 9 children: is that number of children too low, average, or too high?).

13. Numerical knowledge (1 subtask, C31). This task consists of questions related to numerical knowledge of specific facts such as the number of days in a week.

Each item of the EC 301 was rated 2 points for a correct response and 0 points for error. However, in a few tasks, 1 point can be awarded (i.e.., if the patient gives the correct response after requesting repetition of the item). All subjects completed the battery.

\section{Statistical analysis}

The Chi-square $\left(\chi^{2}\right)$ test was applied (without the Yates correction) to compare categorical data. Differences among averages of continuous data were tested employing parametric and non-parametric tests. These tests without exception displayed similar results. Therefore, only the results of the parametric tests were demonstrated. The Student T test for independent samples and the Mann-Whitney (U) test for non-parametric ones were utilized. The Spearman coefficient of correlation $r$ was employed to evaluate the relationship among continuous variables. The probability ( $p$ ) under 0.05 was considered for indicating statistical significance except when a potential problem of multiple comparisons was identified. In this case, we used the Bonferroni correction. All tests were bicaudal. A ninety-five percent confidence interval $(\mathrm{Cl})$ was calculated for the differences between averages and odds ratio (OR).

\section{RESULTS}

Table 1, displays the performance of the participants in the subtests of the EC 301 battery, with values obtained between $70.5 \%$ and $99.6 \%$ of accuracy in the 31 subtests applied. Regarding the accomplishment of the participants in the EC 301 battery, when researching gender, we confirmed that there was no statistically significant difference between the performance of males and females (Table 2).

Table 2. Comparison of the scores between males and females in the subtests of the EC 301 test battery.

\begin{tabular}{|c|c|c|c|c|c|c|}
\hline Subtests & Difference between averages & \multicolumn{3}{|c|}{$95 \% \mathrm{Cl}$ (diference) } & $t(42)$ & $\mathrm{p}$ \\
\hline $\mathrm{Cl}$ & -1.1 & -9.0 & a & 6.9 & -0.3 & 0.788 \\
\hline $\mathrm{C} 2$ & -5.2 & -13.3 & a & 2.9 & -1.3 & 0.206 \\
\hline $\mathrm{C} 3$ & -19.9 & -38.4 & a & -1.5 & -2.2 & 0.035 \\
\hline $\mathrm{C} 4$ & -0.6 & -2.2 & a & 1.0 & -0.7 & 0.479 \\
\hline $\mathrm{C} 5$ & -0.6 & -2.2 & a & 1.0 & -0.7 & 0.479 \\
\hline C6 & -3.0 & -11.5 & a & 5.4 & -0.7 & 0.473 \\
\hline $\mathrm{C7}$ & 1.5 & -6.6 & a & 9.5 & 0.4 & 0.710 \\
\hline $\mathrm{C} 8$ & -6.4 & -14.1 & a & 1.4 & -1.7 & 0.106 \\
\hline $\mathrm{C9}$ & -1.5 & -4.3 & a & 1.4 & -1.0 & 0.315 \\
\hline $\mathrm{C} 10$ & -6.8 & -23.7 & $a$ & 10.1 & -0.8 & 0.423 \\
\hline $\mathrm{C} 11$ & -5.4 & -17.7 & a & 6.9 & -0.9 & 0.380 \\
\hline $\mathrm{C} 12$ & -11.1 & -25.4 & a & 3.1 & -1.6 & 0.123 \\
\hline $\mathrm{C} 13$ & -3.5 & -13.6 & a & 6.6 & -0.7 & 0.487 \\
\hline $\mathrm{C} 14$ & -8.5 & -19.9 & a & 3.0 & -1.5 & 0.144 \\
\hline $\mathrm{C} 15$ & -7.8 & -21.6 & a & 5.9 & -1.1 & 0.258 \\
\hline $\mathrm{Cl} 6$ & 4.9 & -0.5 & $a$ & 10.4 & 1.8 & 0.073 \\
\hline $\mathrm{Cl7}$ & -3.6 & -15.1 & $a$ & 7.9 & -0.6 & 0.535 \\
\hline $\mathrm{C} 18$ & -4.6 & -9.3 & $a$ & 0.2 & -1.9 & 0.058 \\
\hline $\mathrm{C} 19$ & -6.3 & -18.4 & $a$ & 5.8 & -1.0 & 0.300 \\
\hline $\mathrm{C} 2 \mathrm{O}$ & -10.3 & -22.6 & $a$ & 2.0 & -1.7 & 0.097 \\
\hline $\mathrm{C} 21$ & -6.8 & -18.7 & $a$ & 5.1 & -1.2 & 0.254 \\
\hline $\mathrm{C} 22$ & -13.1 & -31.8 & a & 5.6 & -1.4 & 0.166 \\
\hline $\mathrm{C} 23$ & -3.4 & -22.0 & $a$ & 15.3 & -0.4 & 0.718 \\
\hline C24 & -10.9 & -31.8 & $a$ & 9.9 & -1.1 & 0.296 \\
\hline $\mathrm{C} 25$ & 1.6 & -24.3 & $a$ & 27.5 & 0.1 & 0.901 \\
\hline $\mathrm{C} 26$ & -8.0 & -26.2 & $a$ & 10.2 & -0.9 & 0.380 \\
\hline $\mathrm{C} 27$ & 2.8 & -17.1 & $a$ & 22.7 & 0.3 & 0.781 \\
\hline C28 & -13.0 & -35.3 & $a$ & 9.3 & -1.2 & 0.245 \\
\hline $\mathrm{C} 29$ & -0.3 & -13.6 & $a$ & 13.0 & 0.0 & 0.966 \\
\hline $\mathrm{C} 30$ & 1.8 & -6.2 & $a$ & 9.9 & 0.5 & 0.648 \\
\hline C31 & -4.8 & -11.4 & a & 1.9 & -1.4 & 0.155 \\
\hline
\end{tabular}

$\mathrm{p}<0.0016$ indicated for statistical significance, according to Bonferroni correction ( $n=44)$; Cl: confidence interval. 
Table 3. Correlation between education and scores obtained in the subtests of the EC 301 test battery.

\begin{tabular}{ccc}
\hline & \multicolumn{2}{c}{ Education } \\
\cline { 2 - 3 } Subtestes & $\mathrm{r}$ & $\mathrm{P}$ \\
\hline $\mathrm{C} 3$ & 0.54 & $<0.001^{*}$ \\
$\mathrm{C} 10$ & 0.64 & $<0.001^{*}$ \\
$\mathrm{C} 14$ & 0.63 & $<0.001^{*}$ \\
$\mathrm{C} 15$ & 0.51 & $<0.001^{*}$ \\
$\mathrm{C} 18$ & 0.47 & $0.001^{*}$ \\
$\mathrm{C} 22$ & 0.72 & $<0.001^{*}$ \\
$\mathrm{C} 28$ & 0.59 & $<0.001^{*}$ \\
\hline
\end{tabular}

$\mathrm{p}<0.0016$ indicated for statistical significance, according to Bonferroni correction $(n=44)$.

Figure represents the average percentages of correct answers obtained in the subtests of the EC 301 battery according to years of schooling. The participants were grouped according to educational levels from 1 to 5,6 to 8,9 to 12 and over 12 years of schooling.

The effect of instruction on performance by the participants in the different subtests of the EC 301 battery was verified by the Spearman coefficients as follows: after correction for multiple comparisons. Table 3, displays that education demonstrated a strong correlation with subtests C 3, C 10, C 14, C 15, C 18, C 22 and C 28.

In Table 4, the subjects were grouped according to age: subjects with up to 59 years composed the junior group and the senior group consisted of those over this age. The average percentages of the correct answers obtained in the subtests of the EC 301 were based on this age division. The importance of age on performance on the controls of the different tests of the EC301 was verified using the Spearman coefficients. After correction for multiple comparisons, we noted that age did not influence the performance of individuals studied in the different subtests.

\section{DISCUSSION}

The main aim of this study was to contribute to our understanding of the underlying mechanisms of mathematical skills of healthy Brazilian individuals. Among the three demographic factors studied (i.e., age, gender and education) only the latter presented significant effects on the majority of the subtests. The main effects of education and the absence of an age and gender effect are in agreement with the previous report by Rosselli ${ }^{20}$.

Initially we analyzed the performance of the population studied in each subtest of the EC 301 battery. We noted that the comparison of the average number of correct answers in each specific subtest of the EC 301 battery (Table 1), and the scores found ${ }^{18}$ were much lower than those of the European population in all of the battery tests. These results might be attributed to the different educa-
Table 4. Correlation between age and scores in the subtests of the EC 301 test battery.

\begin{tabular}{|c|c|c|}
\hline \multirow[b]{2}{*}{ Subtestes } & \multicolumn{2}{|c|}{ Age } \\
\hline & $r$ & $\mathrm{p}$ \\
\hline $\mathrm{Cl}$ & 0.04 & 0.816 \\
\hline $\mathrm{C} 2$ & 0.11 & 0.491 \\
\hline $\mathrm{C} 3$ & -0.04 & 0.788 \\
\hline $\mathrm{C} 4$ & -0.26 & 0.090 \\
\hline C5 & -0.26 & 0.090 \\
\hline C6 & 0.01 & 0.944 \\
\hline $\mathrm{C7}$ & -0.16 & 0.313 \\
\hline $\mathrm{C} 8$ & -0.15 & 0.331 \\
\hline C9 & 0.06 & 0.706 \\
\hline $\mathrm{C} 10$ & -0.13 & 0.394 \\
\hline $\mathrm{C} 11$ & 0.09 & 0.577 \\
\hline $\mathrm{C} 12$ & -0.26 & 0.090 \\
\hline $\mathrm{C} 13$ & -0.16 & 0.313 \\
\hline $\mathrm{C} 14$ & 0.02 & 0.874 \\
\hline $\mathrm{C} 15$ & -0.14 & 0.370 \\
\hline $\mathrm{C} 16$ & -0.38 & 0.010 \\
\hline $\mathrm{C} 17$ & -0.22 & 0.152 \\
\hline $\mathrm{C} 18$ & -0.07 & 0.657 \\
\hline $\mathrm{C} 19$ & -0.12 & 0.451 \\
\hline $\mathrm{C} 2 \mathrm{O}$ & -0.05 & 0.768 \\
\hline $\mathrm{C} 21$ & 0.04 & 0.783 \\
\hline $\mathrm{C} 22$ & -0.04 & 0.788 \\
\hline $\mathrm{C} 23$ & -0.10 & 0.501 \\
\hline $\mathrm{C} 24$ & -0.19 & 0.211 \\
\hline $\mathrm{C} 25$ & 0.12 & 0.430 \\
\hline$C 26$ & 0.14 & 0.350 \\
\hline $\mathrm{C} 27$ & -0.21 & 0.167 \\
\hline $\mathrm{C} 28$ & -0.21 & 0.177 \\
\hline $\mathrm{C} 29$ & -0.08 & 0.588 \\
\hline $\mathrm{C} 30$ & -0.19 & 0.223 \\
\hline C31 & -0.01 & 0.968 \\
\hline
\end{tabular}

$\mathrm{p}<0.0016$ indicated for statistical significance, according to Bonferroni correction $(n=44)$.

tional systems, and linguistic factors, such as the graphic construction of the number, since both in German and in French it is grammatically different from Portuguese, Italian and English. For example, in French the number 83 would be represented by quatre vingts trois, 90 would be quatre vingts dix, whereas in German, the numbers starting from 20, are pronounced backward, 93 becomes 3 and 90, drei-und-neunzig. Table 1 demonstrated that in subtests: C22, C24, C25 and C28, the averages of healthy individuals were under 70 . This data displays the broad variety of answers given by the Brazilian participants.

Comparison between genders, (Table 2), indicated no difference regarding sex in all the subtests of the EC 301 battery. In healthy adults, the difference between genders showed an advantage of males over females when the level of education is less than four years ${ }^{18,21}$. Never- 
theless, adults with a higher level of education did not demonstrate any statistically significant difference regarding $\operatorname{sex}^{22}$. Therefore, our findings are similar to those described by the authors cited, since there was no difference between genders ${ }^{17,20}$. We should also consider that the education of $68 \%$ of the sample was over six years and the differences between sex are usually noted when the degree of literacy is less than four years.

This study showed that elementary calculation and number processing tasks are strongly dependent on educational level. The effect of education was significant for complex spoken verbal counting, number transcoding involving a written (but not an oral) response; number comparison especially in alphabetical presentation; mental calculation; written subtractions and multiplications (but not additions). Subjects in the lowest educational group showed specific difficulties with comparison of numbers presented in the digital code and with placing numbers on an analogue number line when presentation of the numbers to be placed was oral. These results suggest both an expected increasing familiarity with writing numbers and performing calculations and arithmetic operations with educational level and a reduced ability to use analogue scales and compare numbers among subjects with a low educational level. Also, poorly educated subjects, but not all those with higher education, performed perfectly on placing multi-digit numbers in order to carry out an operation. This suggests that the rules of how to organize the numbers spatially on a sheet of paper to perform the four basic arithmetical operations were more scrupulously respected by subjects with low familiarity with written calculations ${ }^{18}$.

For the subtests C2, C3, C4, C5, C9, C11, C13, C16, C17 and C31, Dellatolas ${ }^{18}$ did not find any differences concerning education since the subjects included presented a correct rate of $97 \%$ for these tasks. An analysis of multiple regression, achieved in a European study, was conducted for the other 21 subtests from which differences in education were analyzed. This analysis indicated that schooling significantly affected the results of 12 of the 21 subtests of the $\mathrm{EC} 301$ battery evaluated $(\mathrm{Cl}, \mathrm{C} 10, \mathrm{C12}, \mathrm{C} 14, \mathrm{C} 15, \mathrm{C19}$, C20, C21, C22, C27, C28 and C30. The dominant pattern of answers was proportional to the educational level. Nonetheless, the results of the two major educational groups ( 9 to 12 years and > than 12 years of schooling) were similar. The Brazilian participants in the study, displayed differences in education in only 6 of the 31 subtests proposed (C3, C10, C14, C15, C22 and C28), as shown in Table 3.

The disparity in education between this study and those ${ }^{17,18}$, is probably due to the smaller composition of the present sample. Additionally, on comparing the performance of the participants in the two studies, the results of the European participants with education between 3 and 5 years, resulted in a lower effect on the accomplishment of tasks: C1, C10, C15, C22, C24, C27 and C28, with a poorer performance obtained through the total number of points. We believe that this drop was due to the fact that the majority of these tests involved reading and writing, as well as more complex mathematical calculations. This "effect" was not visible in the present study (Figure), in which we verified that the participants with between one and five years of education maintained the same percentage of correct answers, as did those with 9 and 12 years of education and those with over 12 years of schooling ${ }^{17}$.

These results indicate that the low familiarity with writing numbers and the use of representative numerical scales may be compatible with the lower level of instruction. Thus, we can assume that the effect of formal instruction may be a little different, and according to the required qualifications, i.e., in evaluation tests that involve writing or more complex arithmetic calculations ${ }^{18}$. As a matter of fact, we know that normal illiterates display a good performance in free-counting of numbers. Nevertheless, in tests that involve orthographic transcodifications and counting numbers backwards, the performance of illiterate subjects is significantly worse compared to literate ones. Despite the similarities of the two studies, we should point out that in Brazil the level of instruction reported by the population is not always true to reality. Many individuals report more than four years of schooling, but act like functional illiterates, that is, they only know how to write their name and a few isolated words. Thus they can compromise comparisons concerning the level of instruction, particularly when compared with developed nations ${ }^{18,23,24}$.

The hypotheses of the influence of education and social exposition should also be considered. Regarding education, we can presume for example, that subjects with four years of schooling may have different levels of knowledge. This is due to educational differences existing in Brazil. The formation of the elementary and middle school instruction differs, especially between public and private education ${ }^{17}$. Additionally, social exposure can affect number processing and calculation, even when the subject has little instruction. Similarly, professional activities developed over a life-time, might promote direct contact with calculations and arithmetic rules. This is so in professions that require calculations, in which we can find a lower degree of literacy and an above average performance in calculation tests.

The absence of any significant effect on age in the performance of individuals evaluated by the EC 301 battery, in the group, may be related to the fact that aging does not interfere directly on calculations. Prior studies ${ }^{3,25}$ that investigate the correlation between age and calculation report that age did not display any significant role on calcu- 
lation or in terms of processing speed. These findings coincide with those in the present study as noted in Table 4 , in which no differences were observed between ages of individuals in the group. Nevertheless, changes between young and senior adults were mentioned recently ${ }^{26}$, with the observation that older adults used a smaller strategy repertoire, besides, the data also showed age-related differences in strategy execution and selection.

In addition, we believe that the difference concerning age was not confirmed, since from early on, we are exposed to activities involving number processing and calculation. These procedures are employed frequently over the course of our lives and because of their use they would always be active.

In conclusion, regarding the performance of the Brazilian population evaluated in this study, in all the EC 301 battery of tests, we noted that gender and age were not factors influencing performance. However, regarding schooling, the group demonstrated that number processing is composed of some abilities that appear to be strongly dependent on educational level. We also confirmed that in this study the Brazilian population presented lower scores than those of the European population, in all the EC 301 test battery.

\section{REFERENCES}

1. Ardila A, Rosselli, M. Acalculia e dyscalculia. Neuropsychol Rev 2002;12:179-231.

2. Hècaen H, Angelergues R, Houiller S. Les Variétés cliniques des acalculias au cours des lesions rétrorolandiques: Apprche statistique du problème. Neurologique 1961;105:85-103.

3. Deloche S, Seron X, Larroque C, et al. Calculation and number processing: assessment battery: role of demographic factors. J Clin Exp Neuropsychol 1994;16:195-208.

4. Rosselli M, Ardila A. Calculation deficit in patients with right and left hemisphere damage. Neuropsychologia 1989;27:607-617.

5. Basso A, Burgio F, Caporali A. Acalculia, aphasia and spatial disorders in left and right brain-damaged patients. Cortex 2000;36:265-279.

6. Basso A. Caporali, P. Faglioni. Spontaneous recovery from acalculia. J Int Neuropsych Soc 2005;11:99-107.

7. Mantovan J, Audet T,Breton, MF. The breakdown of calculation procedures in Alzheimeir`s disease. Cortex 1999;35:21-38.

8. Grafman J, Kampen D, Rosenberg J, Salazar AM, Boller F. The progressive breakdown of number processing and calculation ability: a case study. Cortex 1989;25:121-133.

9. Alcañiz MPS, Marín JAL, Bailén, JRA. Procesamiento numérico y cálculo: evidencia de un caso desde la Neuropsicología cognitiva. Rev Neurol 2003;36:817-820.
10. Alonso D, Fuentes J. Mecanismos cerebrales del pensamiento matemático. Rev Neurol 2001;33:568-576.

11. Cipolotti l, Butterworth B, Denes G. A specific deficit for numbers in a case of dense acalculia. Brain 1991;114:2619-2637.

12. Ashkenazi S, Henik A, Ifergane G, Shelef I. Basic numerical processing in left intraparietal sulcus (IPS) acalculia. Cortex 2008;44:439-448.

13. Chochon F, Cohen L, Van de Mootele PF, Dehaene S. Differential contributions of the left and right inferior lobules to number processing. J Cogn Neurosci 1999;11:17-63.

14. Cohen L, Dehaene S, Chochon F, Lehéricy SE, Naccache L. Language and calculation within the parietal lobe: a combined cognitive anatomical and fMRI study. Neuropsychologia 2000; 38:1426-1440.

15. Vitali P, Tettamanti M, Abutalebi J, et al. Recovery from anomia: effects of specific rehabilitation on brain reorganisation: An er-fMRI study in 2 anomic patients. Brain Lang 2003;87: 126-127.

16. Bernal B, Ardila A, Altman NR. Acalculia: an fMRI study with implications with respect to brain plasticity. Int J Neurosci 2004;114:701-703.

17. Deloche G, Souza L, Braga LW,Dellatolas G. A calculation and number processing battery for clinical application in illiterates and semi-literates. Cortex 1999;35:503-521.

18. Dellatolas G, Deloche G, Basso A, Salinas DC. Assessment of calculation and number processing using the EC-301 battery: cross-cultural normative data and application to left-andright brain damage patients. J Int Neuropsychol Soc 2001;7: 840-859.

19. Ardila A, Galeano, LM, Rosselli, M. Toward a model of neuropsychological activity. Neuropsychol Rev 1998;8:177-189.

20. Rosselli M, Ardila A, Rosas P. Neuropsychological assessment in illiterates. II. Language and praxic abilities. Brain Cog 1990; 12:281-296

21. Kimura, D. Sex and cognition. Cambrige; a Bradford Book, 1999.

22. Hyde JS, Fennema E. Lamon SJ. Gender differences in mathematics performance: a meta-analysis. Psychol Bull 1990;107: 139-155.

23. Dehaene S. Varieties of numerical abilities. Cognition 1992; 44:1-42.

24. Donelle L, Hoffman-Goetz L, Arocha JF. Assessing health numeracy among community-dwelling older adults. J Health Commun 2007;12:651-665.

25. Villardita C, Cultrera S, Cupone V, Mejia R. Neuropsychological test performance and normal aging. Arch Gerontol Geriatry 1985;4:311-319.

26. Lemaire P, Arnaud L. Young and older adults' strategies in complex arithmetic. Am J Psychol 2000;121:1-16. 